\title{
Erratum to: Editorial: Cost-effective analyses in Breast Cancer Research and Treatment
}

Marc E. Lippman - Stephen Ethier •

Daniel F. Hayes

Published online: 23 January 2010

(C) Springer Science+Business Media, LLC. 2010

Erratum to: Breast Cancer Res Treat (2009)

115:221-222

DOI 10.1007/s10549-009-0414-1

Author would like to add the Title "Editorial" to this article and hence the article title will be as given below.

Editorial: Cost-effective analyses in Breast Cancer Research and Treatment

The online version of the original article can be found under doi:10.1007/s10549-009-0414-1.

M. E. Lippman

Department of Medicine, University of Miami Miller

School of Medicine, Miami, FL, USA

e-mail: mlippman@med.miami.edu

S. Ethier

Breast Cancer Program, Karmanos Cancer Institute,

Detroit, MI, USA

D. F. Hayes $(\bowtie)$

Department of Internal Medicine, University of Michigan

Health System, Ann Arbor, MI, USA

e-mail: hayesdf@umich.edu 